\title{
Acquired Heart Block: A Possible Complication of Patent Ductus Arteriosus in a Preterm Infant
}

\author{
Monika Grasser ${ }^{\mathrm{a}} \quad$ Christoph Döhlemann $^{\mathrm{b}} \quad$ Rashmi Mittal $^{\mathrm{a}}$ Holger Till $^{\mathrm{c}}$ \\ Hans-Georg Dietz ${ }^{c}$ Georg Münch ${ }^{a}$ Andreas Holzinger ${ }^{a}$ \\ Divisions of a Neonatology and ${ }^{b}$ Pediatric Cardiology, Department of Pediatrics, and ${ }^{\mathrm{C} D e p a r t m e n t}$ of \\ Pediatric Surgery, Dr. von Hauner Children's Hospital, Ludwig Maximilians University, Munich, Germany
}

\section{Key Words}

Acquired heart block - Extremely low birth weight infant • Patent ductus arteriosus

\begin{abstract}
A large patent ductus arteriosus (PDA) is a frequently encountered clinical problem in extremely low birth weight (ELBW) infants. It leads to an increased pulmonary blood flow and in a decreased or reversed diastolic flow in the systemic circulation, resulting in complications. Here we report a possible complication of PDA not previously published. On day 8 of life, a male ELBW infant (birth weight $650 \mathrm{~g}$ ) born at a gestational age of 23 weeks and 3 days developed an atrioventricular block (AV block). The heart rate dropped from 168/min to $90 / \mathrm{min}$, and the ECG showed a Wenckebach second-degree AV block and intraventricular conduction disturbances. Echocardiography demonstrated a PDA with a large left-to-right shunt and large left atrium and left ventricle with high contractility. Within several minutes after surgical closure of the PDA, the heart rate increased, and after 30 min the AV block had improved to a 1:1 conduction ratio. Echocardiography after $2 \mathrm{~h}$ revealed a significant decrease of the left ventricular and atrial dimen-
\end{abstract}

\section{KARGER}

Fax +41613061234

E-Mail karger@karger.ch

www.karger.com (c) 2007 S. Karger AG, Basel

$1661-7800 / 08 / 0934-0276 \$ 24.50 / 0$

Accessible online at:

www.karger.com/neo sions. Within $12 \mathrm{~h}$, the AV block completely reversed together with the intraventricular conduction disturbances. We suggest that PDA with a large left-to-right shunt and left ventricular volume overload may lead to an AV block in an ELBW infant. Surgical closure of the PDA may be indicated.

Copyright $\odot 2007$ S. Karger AG, Basel

\section{Introduction}

Prematurity is associated with a delayed closure of the ductus arteriosus. Due to the decrease in pulmonary vascular resistance after birth, a large left-to-right shunt may result in lung edema and in a decreased pulmonary compliance. Furthermore, the systemic circulation may suffer from a low diastolic flow. Therefore, complications of a large patent ductus arteriosus (PDA) include respiratory insufficiency with or without pulmonary hemorrhage, bronchopulmonary dysplasia, necrotizing enterocolitis, and low urine output. A low cerebral perfusion secondary to a PDA has been proposed to be a significant risk factor for intraventricular hemorrhage [1]. Recently, PDA has been found to be a risk factor for cerebellar hem-

Prof. Christoph Döhlemann

Dr. von Hauner Children's Hospital, Ludwig Maximilians University

Lindwurmstrasse 4, DE-80337 Munich (Germany)

Tel./Fax +498151 12970

E-Mail christoph.doehlemann@med.uni-muenchen.de 

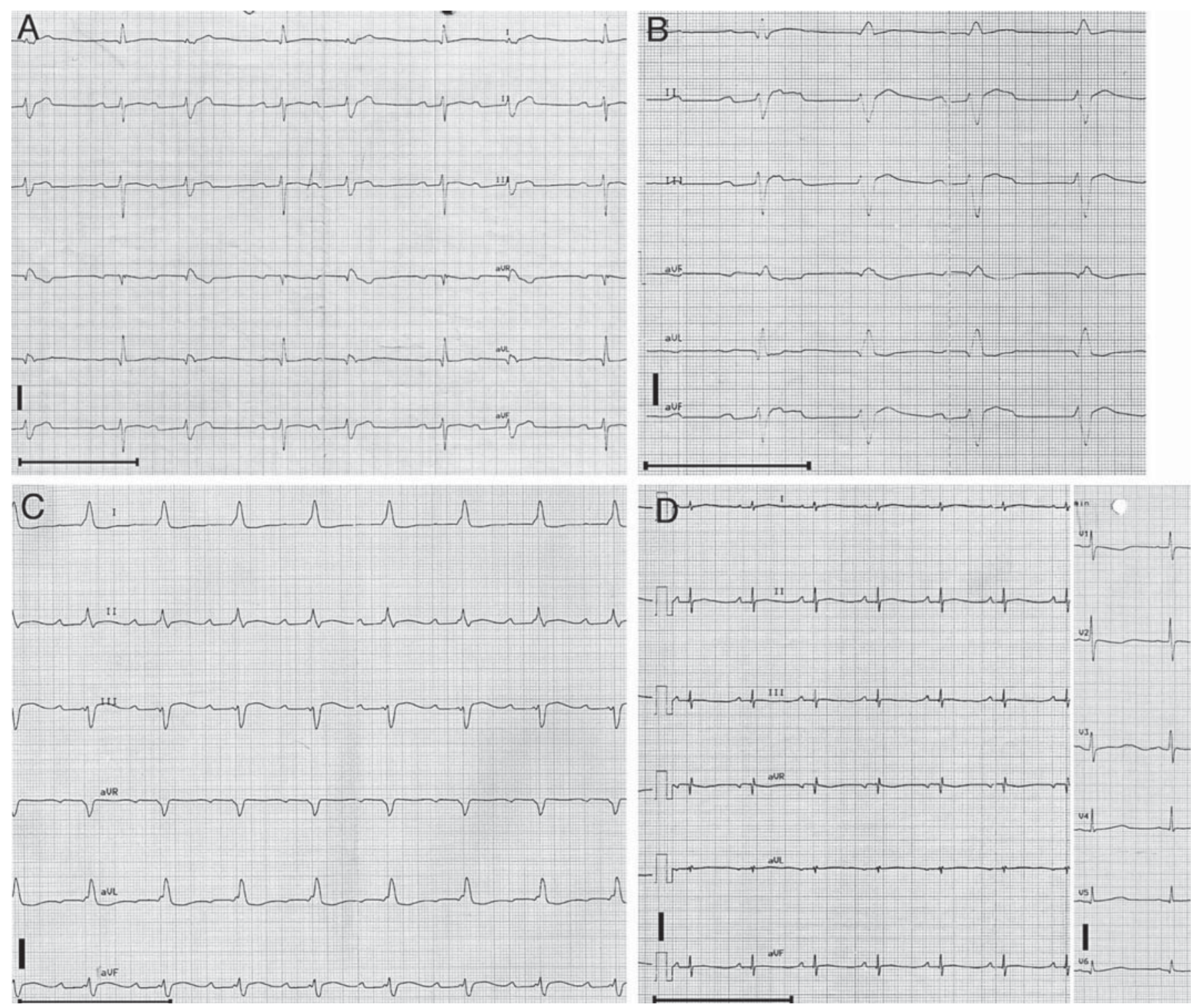

Fig. 1. Electrocardiographic (ECG) recordings. Paper speed 50 $\mathrm{mm} / \mathrm{s}$. Horizontal bars represent $1 \mathrm{~s}$, vertical bars $1 \mathrm{mV}$. A ECG recording after sudden bradycardia. Second-degree AV block with progressive prolongation of the P-R interval (0.16-0.25 s) prior to the blocked $\mathrm{P}$ wave hidden in the $\mathrm{T}$ wave of every second QRS complex. Conduction ratio 3:2, P-P interval $0.40 \mathrm{~s}, \mathrm{f}=150 /$ $\mathrm{min}$. The first conducted QRS complex (duration $0.06 \mathrm{~s}$ ) shows a QRS axis $\left(-50^{\circ}\right)$ oriented superior to the left (left anterior hemiblock); the second QRS complex (duration 0.08 s) shows a prolongation of the terminal forces (wide $\mathrm{R}^{\prime}$ in $\mathrm{aVR}$ ) to the right (left anterior hemiblock plus right bundle branch block, i.e., bifascicular block). Because of this intraventricular conduction disturbance, the block can be localized in the His-Purkinje region. The

blocked $\mathrm{P}$ wave can thus be interpreted as a trifascicular block despite the Wenckebach type of the AV block, which is usually caused by a conduction disturbance in the AV node. B ECG $5 \mathrm{~h}$ later, before ligation of the ductus arteriosus. Increased QRS duration $(0.1 \mathrm{~s})$; complete left bundle branch block. There is still grade $2 \mathrm{AV}$ block or total AV block grade 3. Interpolated P-P interval (partly hidden in QRS and S-T) $0.40 \mathrm{~s}, \mathrm{f}=150 / \mathrm{min}$. R-R interval $0.62 \mathrm{~s}, \mathrm{f}=97 / \mathrm{min}$. C ECG $30 \mathrm{~min}$ after duct ligation. Every $\mathrm{P}$ wave is conducted, P-R interval $0.18 \mathrm{~s}$ (AV block grade 1), QRS duration $0.08 \mathrm{~s}$ (left bundle branch block), $\mathrm{f}=116 / \mathrm{min}$. D ECG $12 \mathrm{~h}$ postoperatively. Sinus rhythm, no AV block, P-R interval $0.12 \mathrm{~s}$, normal QRS (duration $0.04 \mathrm{~s}$, QRS angle $+68^{\circ}$ ), normal repolarization, R-R interval $0.44 \mathrm{~s}, \mathrm{f}=137 / \mathrm{min}, \mathrm{QT} 0.24 \mathrm{~s}$, QTc $0.39 \mathrm{~ms}$. 
Table 1. Vital parameters, blood analyses, oxygen requirement, fluid intake, and diuresis in relation to the onset of AV block and surgical PDA ligation

\begin{tabular}{|c|c|c|c|c|c|c|c|}
\hline & $-11 \mathrm{~h}$ & $\pm 0 \mathrm{~h}$ & $2 \mathrm{~h}$ & $6 \mathrm{~h}$ & $8 \mathrm{~h}$ & $10 \mathrm{~h}$ & $13 \mathrm{~h}$ \\
\hline Heart rate/min & 168 & 90 & 92 & 91 & 118 & 110 & 125 \\
\hline \multicolumn{8}{|l|}{ Blood pressure, $\mathrm{mm} \mathrm{Hg}$} \\
\hline Systolic/diastolic & $56 / 24$ & $46 / 22$ & $42 / 19$ & $45 / 17$ & $52 / 28$ & $51 / 26$ & $52 / 28$ \\
\hline Mean & 33 & 32 & 28 & 24 & 36 & 29 & 35 \\
\hline Sodium, mM & 137 & 131 & 129 & 129 & 132 & 135 & 138 \\
\hline Potassium, mM & 3.3 & 3.9 & 3.6 & 4.1 & 4.3 & 4.2 & 4.4 \\
\hline Ionized calcium, mM & 1.41 & 1.42 & 1.39 & 1.40 & 1.39 & 1.44 & 1.44 \\
\hline $\mathrm{pH}$ & 7.28 & 7.26 & 7.28 & 7.29 & 7.37 & 7.35 & 7.27 \\
\hline $\mathrm{pCO}_{2}, \mathrm{~mm} \mathrm{Hg}$ & 40.1 & 44.1 & 39 & 41.2 & 35.6 & 39.4 & 46.1 \\
\hline Base deficit, mM & 7.0 & 6.4 & 7.3 & 6 & 3.8 & 3.3 & 4.9 \\
\hline $\mathrm{HCO}_{3}, \mathrm{mM}$ & 18.3 & 18.6 & 18.1 & 19.2 & 21.2 & 21.5 & 19.8 \\
\hline $\mathrm{FiO}_{2}$ & 0.57 & 0.60 & 0.85 & 0.85 & 0.67 & 0.48 & 0.48 \\
\hline Fluid intake, $\mathrm{ml} / \mathrm{kg} /$ day & $664^{\mathrm{a}}$ & 169 & 101 & 123 & 116 & 103 & 192 \\
\hline Diuresis, $\mathrm{ml} / \mathrm{kg} /$ day & $515^{\mathrm{a}}$ & 446 & 456 & 142 & 422 & 472 & 470 \\
\hline
\end{tabular}

PDA ligation was performed $6 \mathrm{~h}$ and $30 \mathrm{~min}$ after onset of the AV block. Note the improvements of diastolic and mean blood pressures and oxygenation after the ligation. Serum electrolyte disturbances were excluded from being the cause of the AV block.

a Values refer to 24-hour intervals prior to onset of the AV block.

orrhage in preterm infants [2]. An increased blood flow in the pulmonary circulation, secondary to a large PDA, leads to a dilation of left atrium (LA) and left ventricle (LV) due to volume overload. Here we report on a hitherto unknown complication of a large PDA in an extremely low birth weight (ELBW) infant. Due to the dilation of the LV, a Wenckebach second-degree atrioventricularblock (AV block), resulting in bradycardia, developed. Urgent surgical closure led to an immediate normalization of the heart rate and to the normalization of the ECG findings within $12 \mathrm{~h}$.

\section{Case Report}

A male infant was born by normal vaginal delivery to a healthy 19 -year-old gravida 3 para 2 at a gestational age of 23 weeks and 3 days. The birth weight was $650 \mathrm{~g}$, and the Apgar scores were 6 and 9 at 1 and $5 \mathrm{~min}$, respectively. The umbilical artery $\mathrm{pH}$ was 7.40. The patient had respiratory distress syndrome requiring mechanical ventilation, and a single dose of surfactant was given (60 $\mathrm{mg}$ Curosurf $\left.{ }^{\circledR}\right)$. The infant also received a $15-\mathrm{ml} / \mathrm{kg}$ bolus of normal saline, $60 \mathrm{mg} / \mathrm{m}^{2}$ hydrocortisone, and $10 \mu \mathrm{g} / \mathrm{kg} / \mathrm{min}$ dopamine due to persistent arterial hypotension on day 1 of life. Routine investigations, including serum electrolytes, were normal, and antibiotic treatment was started. On day 2 of life, the patient's condition was stable, and oral feeds were begun. The infant had polyuria from birth and a weight loss of $20 \%$ until day 4 of life, when a large PDA (3 $\mathrm{mm}$ in diameter) with a left-to-right shunt was detected, but failed to respond to two doses of indomethacin $(0.2 \mathrm{mg} / \mathrm{kg})$. On day 6 of life, before the third planned dose of indomethacin, the infant developed clinical and radiological signs of necrotizing enterocolitis with intestinal perforation. He was transferred to our hospital, and an emergency laparotomy was carried out. Necrosis of the terminal ileum was revealed, and an ileostoma was created after resection of the affected segment. Postoperatively, the heart rate was $160 / \mathrm{min}$ with a mean blood pressure of $25 \mathrm{~mm} \mathrm{Hg}$. Serum electrolytes were normal, and blood gas analysis revealed metabolic acidosis with a base deficit of 12 mM which was corrected with intravenous sodium bicarbonate. The diuresis had been low immediately after abdominal surgery, but increased to the former values of approximately $480 \mathrm{ml} / \mathrm{kg} /$ day thereafter; $48-24 \mathrm{~h}$ before the sudden AV block, the patient had a negative fluid balance due to massive diuresis of $537 \mathrm{ml} / \mathrm{kg} /$ day despite a large intravenous volume administration of $435 \mathrm{ml} /$ $\mathrm{kg} /$ day. During $24 \mathrm{~h}$ before the onset of the AV block, the patient had received total fluids of $664 \mathrm{ml} / \mathrm{kg} / \mathrm{day}$, in addition to dobutamine $(15 \mu \mathrm{g} / \mathrm{kg} / \mathrm{min})$ and hydrocortisone to maintain a mean blood pressure $>27 \mathrm{~mm} \mathrm{Hg}$. The diuresis during that interval was $515 \mathrm{ml} / \mathrm{kg} /$ day.

On day 8 (body weight $590 \mathrm{~g}$ ), the heart rate suddenly dropped from $168 / \mathrm{min}$ to $90 / \mathrm{min}$. The body temperature was $37.3^{\circ} \mathrm{C}$. The ECG showed a second-degree AV block type I (Wenckebach; conduction ratio 3:2), with increasing intraventricular conduction disturbance (fig. 1A, B), which was interpreted as an incomplete trifascicular block [3]. Color Doppler echocardiography revealed a PDA (3 mm in diameter) with a large left-to-right flow (maximum $2.3 \mathrm{~m} / \mathrm{s})$. The LV was large with an end-diastolic diameter of $14 \mathrm{~mm}$ - normal $<10 \mathrm{~mm}[4-6]$ - and a high contractility (frac- 
tional shortening in M-mode 41\%). The LA was also dilated (11 $\mathrm{mm}$ ), with an increased LA/aortic root ratio of 2.2. A grade $2 \mathrm{mi}-$ tral regurgitation was noted. The right ventricle was not dilated (right ventricular end-diastolic diameter $3 \mathrm{~mm}$ ). A left-to-right shunt through the foramen ovale was seen. Moreover, there was a reverse diastolic flow through the celiac artery. A chest X-ray showed an enlarged heart and an increased pulmonary perfusion. An intravenous bolus of atropine $(10 \mu \mathrm{g} / \mathrm{kg})$ had only a little effect on the AV block, the AV conduction ratio changing from 3:2 to $4: 3$ (heart rate $94 / \mathrm{min}$ ). Orciprenaline ( 3 bolus doses of $10 \mu \mathrm{g} / \mathrm{kg}$, followed by a continuous infusion of $10 \mu \mathrm{g} / \mathrm{kg} / \mathrm{h}$ ) had no effect on the AV block. The oxygenation index deteriorated from 8.8 to 24.0 , and the blood pressure decreased subsequently (table 1). Laboratory data showed a mild reversible metabolic acidosis and mild hyponatremia, normal values for potassium, calcium (table 1$)$, creatinine kinase $(25 \mathrm{U} / \mathrm{l})$, and aspartate transferase ( 28 $\mathrm{U} / \mathrm{l})$, and mildly increased serum creatinine $(0.6 \mathrm{mg} / \mathrm{dl})$ and urea nitrogen $(18 \mathrm{mg} / \mathrm{dl})$ values.

Five hours after onset of the AV block, a decrease in LV contractility was noted (fractional shortening $31 \%$, LV end-diastolic diameter $13 \mathrm{~mm}$ ), along with an increase in the right ventricular end-diastolic diameter $(6 \mathrm{~mm})$, with an unchanged large left-toright shunt through the PDA.

Because of (1) the insufficient effects of atropine and catecholamines on the AV block, (2) exclusion of common causes of the AV block, (3) high fluid requirement to maintain adequate blood pressure, and (4) decrease of diuresis, we decided for surgical closure of the PDA. It was performed without unusual blood loss or other complications $6 \mathrm{~h}$ and $30 \mathrm{~min}$ after the onset of the AV block. Within minutes after closure, the blood pressure rose from $38 / 15$ (mean 24) $\mathrm{mm} \mathrm{Hg}$ to $48 / 28$ (mean 39) $\mathrm{mm} \mathrm{Hg}$ and the heart rate from $90 / \mathrm{min}$ to $110 / \mathrm{min}$. The ECG $30 \mathrm{~min}$ later showed a decrease in the degree of heart block with a 1:1 conduction ratio (fig. 1C). A complete normalization of the ECG was observed $12 \mathrm{~h}$ after ductal ligation (fig. 1D). Doppler echocardiography $2 \mathrm{~h}$ after ligation showed a significant decrease in LV end-diastolic diameter (from 14 to $7 \mathrm{~mm}$ ) and LV end-systolic diameter (from 8 to $3 \mathrm{~mm}$ ) and LA (from 11 to $7 \mathrm{~mm}$, LA/aortic root ratio dropping from 2.2 to 1.3 ) and a normal arterial flow curve with positive diastolic flow in descending aorta and celiac artery. No recurrence of AV block occurred. The infant was extubated on day 51 of life. Pre- and postoperative echocardiographic studies excluded a structural cardiac defect. At a corrected age of 3 months, the echocardiography findings were normal for the infant's weight of $3.9 \mathrm{~kg}$.

\section{Discussion}

We reported a PDA in an ELBW infant with a large left-to-right shunt and enlarged LA and LV, in whom a second-degree AV block and intraventricular conduction disturbances occurred and resolved promptly after surgical PDA closure. LV and LA dimensions decreased significantly after closure of the PDA, as it was reported in 40 ELBW cases with PDA ligation [4]. AV block and intraventricular conduction disturbances have not been described previously as a complication of PDA in an ELBW infant.

In the presence of a large left-to-right shunt through the PDA, there is a decreased systolic and a reverse diastolic flow in the descending aorta. This causes a diastolic steal from the abdominal organs which may lead to the development of necrotizing enterocolitis in preterm infants [7], as observed our patient. The large leftto-right shunt also results in volume overload of the left heart, resulting in a large LA and LV. In our patient, the LV was enlarged which may have been due to a combination of the large left-to-right shunt and the excessive fluid requirements to maintain a normal blood pressure. The prompt improvement of the AV block after ligation of the duct with a decrease of atrial and ventricular dimensions and an increase of blood pressure and perfusion leads to the suggestion that the increased LV dimensions may have prolonged the path of the electrical excitation, leading to a fascicular AV block. Possibly, a decrease in the coronary arterial perfusion due to the low diastolic pressure may also have contributed.

Metabolic disturbances such as hyperkalemia and hypocalcemia - potential causes of AV block in newborn infants [8-10] - were excluded in multiple blood analyses. There was also no evidence of myocarditis or cardiomyopathy during the follow-up period.

We suggest that LV enlargement and low coronary flow due to a large left-to-right shunt through a PDA may lead to an AV block in ELBW infants. Surgical closure of the PDA may be indicated.

\section{Acknowledgment}

The authors thank Dr. Markus Loeff for careful reading of the manuscript.

\section{References}

1 Evans N, Kluckow M: Early ductal shunting and intraventricular haemorrhage in ventilated preterm infants. Arch Dis Child Fetal Neonatal Ed 1996;75:F183-F186.

2 Limperopoulos C, Benson CB, Bassan $\mathrm{H}$, Disalvo DN, Kinnamon DD, Moore M, Ringer SA, Volpe JJ, du Plessis AJ: Cerebellar hemorrhage in the preterm infant: ultrasonographic findings and risk factors. Pediatrics 2005; $116: 717-724$

3 Gumbiner $\mathrm{CH}$ : Bundle branch block and fascicular block; in Gilette PC, Garson A (eds): Pediatric Cardiac Dysrhythmias. New York, Grune \& Stratton, 1984, pp 405-419. 
4 Baylen B, Meyer RA, Korfhagen J, Benzing G 3rd, Bubb ME, Kaplan S: Left ventricular performance in the critically ill premature infant with patent ductus arteriosus and pulmonary disease. Circulation 1977;55:182188.

5 Skelton R, Gill AB, Parsons JM: Reference ranges for cardiac dimensions and blood flow velocity in preterm infants. Heart 1998; 80:281-285.
6 Walther FJ, Siassi B, King J, Wu PY: Echocardiographic measurements in normal preterm and term neonates. Acta Paediatr Scand 1986; $75: 563-568$.

7 Musewe NN, Olley PM: Patent ductus arteriosus; in Freeman RM, Benson LN, Smallhorn JF (eds): Neonatal Heart Disease. London, Springer, 1992, pp 593-609.

8 Mendicini M, Chiarini M, Scalamandre A, Savignoni PG, Bucci G: Acquired atrioventricular block in the premature newborn: new observations on the etiopathogenesis and therapy (in Italian). Riv Clin Pediatr 1967;80:1-15.
9 Bucci G, Chiarini M, Scalamandre A, Savignoni PG, Mendicini M: 2:1 atrio-ventricular block from metabolic imbalance in the newborn premature infant. Schweiz Med Wochenschr 1966;96:377-383.

10 Griffin JH: Neonatal hypocalcemia and complete heart block. Am J Dis Child 1965; 110:672-675. 